\title{
Research on the Network Marketing Channel Strategy in Sports Life: an Empirical Analysis based on College Students
}

\author{
Yadong Ren \\ Huaiyin Normal University, Huaian city, Jiangsu province, 223300, China \\ *Corresponding author: Yadong Ren(jlryd@163.com)
}

\begin{abstract}
With the development of information technology, Internet age has changed the way of people's life in learning, entertainment, communication, consumption and other areas. Network has a positive effect on study and life for college student, but also brings a lot of negative impact. In this paper, we test the influence of internet content and try to find out how it could impact the college students' sports life. By using empirical analysis, the result shows that the main reason of college students' motivation to participate in sports activities is to have a strong physique, there is a significant correlation between the Internet and college students' sports life style. Internet will significantly affect the sports consumption and sports interest of college students. On this basis, we put forward some advices.
\end{abstract}

Keywords: Network Marketing, E-commerce, Sports life, College student, Internet platform

\section{Introduction}

The 21st century is the Internet era; people's life has begun to from the real space to "cyberspace" extension. According to China Internet Network Information Center show that as of the end of 2014, China's Internet users reached 643 million, Internet penetration rate of $46.9 \%$. China's number of Internet users continues to maintain rapid growth, only a year in 2013 increased by 14.42 million people. The rapid development of the Internet, not only strongly impact the social economic form, influence the social economic life, but also a strong impact on the traditional ideas and thinking mode, and the rapid popularization and wide application of the Internet is learning, entertainment, communication, consumption and other areas of deep change people's way of life. Statistics report shows that the proportion of Internet users aged 20-29 years of 30.7\%, accounting for the largest proportion in the overall Internet users, this age group of college students, college students are active, easy to accept the new ideas and new things, the network is one of the most active groups, college students' life style has been greatly affected by the network. According to the survey, the proportion of College Students' leisure life is the highest proportion of Internet and makes friends, which is a major way of life of college students; the main energy is put on the play. Network in the study of college students, life has a positive role in the negative impact, because the Internet is over, the students have sleep disorders, the phenomenon of loss of appetite, weight loss, the phenomenon of students with mental retardation, the student social activities decreased, even suicidal ideation, seriously affected the physical and mental health of College students. These phenomena have a profound influence on the normal order of the school, the rhythm of life and the behavior of individual health. It can be said that the great influence of the network to college students is a reality that cannot be ignored.

The life style of college students in the Internet age is a special group. It is different from other social groups in the contemporary society, but also in the history of college students. Along with the popularity of the Internet, it makes the network culture of the 
Internet as new cultural characteristics of the Internet era. The media environment of the Internet age has attracted college students with its multiple, complex, entertaining, interactive and virtual. It becomes the main channel for them to understand the outside world, and has a profound influence on their behavior. While the Internet has brought convenience to college students' life and communication, and the improvement of the level of awareness, the negative influence should not be ignored. Such as the coexistence of real and virtual Internet, they can easily lead to the imbalance of interpersonal relationship and the alienation of network personality. These problems affect the normal social process of college students; we need to pay attention to this situation.

\section{Literature Review}

\subsection{Marketing Network}

On the definition of marketing, Western marketing scholars from different perspectives and development perspectives are defined, which is representative of the American Marketing Association in 1985 to do the definition: marketing is the idea, product and service design, setting price, sales promotion and distribution of the process, and thus to meet the exchange of personal and organizational goals. In this definition, it can be clearly seen that the seller in the identification, analysis, evaluation, selection and utilization of market opportunities, based on the needs of the target market to meet the needs of customers, there are plans to organize the economic activities of enterprises, the process of completing sales. Network marketing it comes from the traditional marketing, but with the traditional marketing has a huge difference. Network marketing is characterized by the use of the Internet as a means to achieve the purpose of marketing. With regard to the definition of its concept, the development of the times is changing rapidly. But as a marketing tool, its essence is relatively stable. Broadly speaking, the Internet as the main means to carry out, in order to achieve certain marketing purposes of marketing activities, can be referred to as network marketing. That is to say, network marketing is the whole process of enterprise development, from the information publishing, information collection, to the development of online transactions in the ecommerce stage, online marketing has been an important content. From the perspective of marketing, network marketing is an integral part of the overall marketing strategy, which is based on the Internet to create an online business environment, in order to achieve the overall business objectives of the enterprise. The definition of network marketing and traditional marketing is the same, is to understand the needs of customers and meet them; at the same time, it is no longer a promotion so simple, but throughout the marketing process: from the product launch before the market research, product design and manufacturing process, and then to marketing communications, and then to after-sales service, network marketing through the entire process.

Whether traditional marketing or network marketing, its fundamental purpose is to achieve sales, for any one of the enterprises, the basis of its business activities is the establishment of relations with the external environment. Internet based promotion and marketing and the rise of the Internet Marketing, in fact, is to create a network operating environment. That is to say, whether it is the traditional marketing or emerging network marketing, they are all following a timeless Law: the promotion and sales of unlimited cycle. Network marketing experts pointed out that the so-called online business environment, refers to the enterprise internal and external and to carry out online business activities related to the environment, including the enterprise website itself, customers, network service providers, partners, suppliers, vendors, related industries, such as network environment, etc. Therefore, the emergence of the Internet, it is only a change in the business environment; the environment is changed, but also changed the traditional promotion and sales. Throughout China's social development situation, as a new strategic 
industry in the Internet industry, it is playing an irreplaceable role in the promotion of social progress, the benefit of people's life and so on. The prosperity and development of the Internet industry is also bound to bring a rare opportunity for the innovation of the network marketing business. Network marketing investment in the enterprise marketing in the growing, as well as the overall size of the market's strong expansion, the network marketing is involved in the industry and the field will be more extensive, marketing approach is increasingly diverse, marketing products and services in the creative, quality, effectiveness and accuracy, etc.. And the rapid development of e-commerce, mobile Internet, network community, micro blog, which makes the network platform, open, interactive, has been reflected, but also for its innovation in service and business model has brought more space.

\subsection{Sports Life Style}

The value of sports life style reflects the relationship between individual, group and society in real life and it is the sum of the value of benefit, utility, and significance in sports activities. The values of the core position in the sports life style, the difference of the sports life style is different from the system values. The reason why a person participated in sports activities is because people have the choice of "how to live" the subjective initiative. The motive is the power source of all human behavior, which is to promote the main body to participate in sports activities, including people's intentions, desires, goals, etc., according to Maslow's theory of hierarchy of needs, motivation comes from the individual's various needs, only when people have the sports needs, will produce the motivation to meet this demand, explicit sports behavior. The form of education is the result of the action subject and the objective conditions. Its performance is achieved by establishing the relationship between the subject and the objective conditions. Sports means rich and varied, including all sports, it is the form of sports activities in the form of intermediary nature of the means, in different sports activities and different objective conditions to play a role, to meet the needs of different levels of college students, so that sports activities in the form of time and space of different characteristics, so as to achieve different results. Sports behavior characteristics, features make sports students have visibility and stability, we also use this visible and explicit activity characteristics to determine the reasonable degree of people's life style, including the way of participation in sports activities, types, means, duration, sports consumption, etc.

Sports activities conditions including natural conditions, social conditions and their own conditions, natural conditions: natural conditions, including physical activity can take advantage of all the natural geographical environment; artificial constraints sports lifestyle natural conditions mainly all kinds of sports facilities; social conditions: social conditions factor is a large and complex systems, including social structure political, economic, cultural, education, customs, habits and fashion, mass media, and many other macro-social conditions, including people's own education level, income level, consumption level and structure, leisure time and other micro-social conditions; own condition: Sports activities with other activities in different times of a feature is that the people themselves are the most important condition, that the activities of the main body, but also the activities of the object, the object of action sports. Sports conditions of this study is mainly: gender, age, health, family history, personal interests and other natural conditions, economic conditions and other social conditions, as well as sports activities, projects, time and frequency of their own conditions. 


\section{Research Methods and Data}

\subsection{Research Methods}

In higher education, the highest level of education, if college students do not form a good way of life, then to a large extent affect their future life planning and career development, and thus affect the future of the national sports industry, so in the new situation to college students put forward new requirements: cultivate personal control ability and good living habits, in the full enjoyment of the Internet to bring great convenience, but also should realize that the Internet community to its own body wide anti. Internet is a "double-edged sword", the development of the network to promote the exchange of human civilization and the world's cultural innovation. These new cultural achievements enrich the content of College Students' sports life style, and expand the college students' sports field, and form a new campus sports environment. However, the network has also brought new contradictions, such as the formation of "network dependence", long-term addiction in the network, ignoring the reality of the moral norms, the ideal and the value of indifference, lack of sense of social responsibility. The research of College Students' sports life style in the Internet era, improving college students' bad living habits, is conducive to Cultivating Contemporary College Students to establish a correct outlook on life, world outlook, values, enhance students' sense of social responsibility and the perseverance of the struggle against bad information, and to ensure the healthy and comprehensive development of contemporary college students.

The sample selected from Huaiyin normal university, a total of 600 copies of questionnaires, follow the principle of social science, the sample range can be controlled in the overall $1 \%$, from the selected campus, professional, campus environment, etc., that the subject of this study can reflect the basic situation and characteristics of College students. Through the database, CNKI and other search engines, query the research results of the domestic and foreign sports life style of college students, studying about the sports lifestyle outstanding masters, doctoral dissertation, and on the sports life style of college students' research papers, access to the social sports, sports psychology, sports lifestyle, and physical education science etc. related works. In addition to the university library, institute of physical education Library and borrow about sports lifestyle related books, statistics software, books and technical analysis. According to the questionnaire survey, we visited 15 college teachers, 23 physical education teachers, to understand the basic situation of college physical education, the development of extracurricular sports activities and students' participation, as well as the factors affecting college students' sports life style.

\subsection{Questionnaire Design}

According to the needs of this research, the literature data were collected and analyzed, and the relevant issues of the national physical fitness tests were collected. The questionnaire was compiled with the relevant expert opinion. 600 questionnaires were distributed, 594 were male and 300 were female. The recovery rate was $99 \%$. The effective rate was 575 . Using SPSS statistical software to describe the statistics, the results shown in Table 1.

Table 1. Statistical Analysis of Sample

\begin{tabular}{|c|c|c|c|c|c|c|c|}
\hline Grade & Gender & Factor & $\begin{array}{c}\text { Sports } \\
\text { Sch. }\end{array}$ & $\begin{array}{c}\text { Foreign } \\
\text { Sch. }\end{array}$ & $\begin{array}{c}\text { Busin. } \\
\text { Sch. }\end{array}$ & $\begin{array}{c}\text { Engin. } \\
\text { Sch. }\end{array}$ & Total \\
\hline \multirow{2}{*}{$\begin{array}{c}\text { Grade } \\
1\end{array}$} & \multirow{2}{*}{ Male } & Number & 19 & 20 & 15 & 9 & 63 \\
\cline { 2 - 8 } & Female & Number & 18.30 & 18.32 & 18.41 & 18.37 & 18.35 \\
\cline { 2 - 8 } & & & 20 & 23 & 11 & 72 \\
\hline
\end{tabular}




\begin{tabular}{|c|c|c|c|c|c|c|c|}
\hline & & Age & 18.37 & 18.31 & 18.25 & 18.31 & 18.32 \\
\hline \multirow{3}{*}{$\begin{array}{c}\text { Grade } \\
2\end{array}$} & \multirow{2}{*}{ Male } & Number & 21 & 22 & 21 & 11 & 76 \\
\cline { 3 - 8 } & & Age & 19.35 & 19.42 & 19.40 & 19.59 & 19.43 \\
\cline { 2 - 8 } & \multirow{2}{*}{ Female } & Number & 20 & 20 & 23 & 12 & 75 \\
\hline & & Age & 19.27 & 19.45 & 19.69 & 19.44 & 19.44 \\
\hline \multirow{3}{*}{$\begin{array}{c}\text { Grade } \\
3\end{array}$} & \multirow{2}{*}{ Male } & Number & 21 & 22 & 21 & 11 & 76 \\
\cline { 2 - 8 } & \multirow{2}{*}{ Female } & Age & 20.33 & 20.36 & 20.41 & 20.37 & 20.41 \\
\cline { 3 - 8 } & & Number & 20 & 20 & 23 & 12 & 75 \\
\hline
\end{tabular}

The use of the Internet requires hardware and software, the hardware is terminal, which means college students handheld devices, such as mobile phones and computers, data can reflect the survey, $83 \%$ of students using smart phones, $91 \%$ of students have a computer, the data shows that the end of the mobile phone and computer and other Internet has been very popular in College students, college students' network age is shown in Table 2.

Table 2. College Students' Network Age Constitute Survey Statistics

\begin{tabular}{|c|c|c|}
\hline Net age & Select number & Percent (\%) \\
\hline 1-3 years & 32 & 5.57 \\
\hline 4-5 years & 163 & 30.09 \\
\hline 5-10 years & 291 & 50.61 \\
\hline More than 10 years & 79 & 13.74 \\
\hline
\end{tabular}

\section{Empirical Analysis}

\subsection{Internet Sports Information}

Through the understanding of College Students Internet browsing content can reflect students' surfing habits and objective, $47 \%$ college students choose to browse and query Webpage learning materials on the Internet, 53\% of the students choose to watch movies, play games and online shopping, further analysis found that, male and female students in Internet content selection have obvious difference, $77 \%$ of the boys is the Internet in order to play the game, and $83 \%$ of the girls choose online shopping, compared with the high school life, personal life of college students physical constraints is relatively small, in the Internet shows that college students self control ability is weak, easy to be Webpage on pictures or advertising to attract. According to the related literature classification of mass media, on the Internet the content is divided into knowledge, news, entertainment, service class, integrated class, and other classes. The contact frequency is divided into regular contact, occasionally, and no three grades, calculated the weighted average of university students the number of Internet sports information content. From Table 3, we can see from the college students' contact with Internet sports information content survey statistics can be seen, sort order is knowledge, news, comprehensive, service, entertainment and other categories.

Table 3. College Students' Access to Internet Sports Information

\begin{tabular}{|c|c|c|c|c|c|}
\hline Content & Frequent & Sometimes & never & total score & Sort \\
\hline Knowledge & 440 & 135 & 0 & 1590 & 1 \\
\hline News & 418 & 157 & 0 & 1568 & 2 \\
\hline Comprehensive & 432 & 78 & 65 & 1517 & 3 \\
\hline Service & 412 & 119 & 44 & 1508 & 4 \\
\hline Entertainment & 401 & 95 & 39 & 1465 & 5 \\
\hline Others & 70 & 85 & 420 & 800 & 6 \\
\hline
\end{tabular}




\subsection{College Students Sports Motivation}

Contemporary college students in the era of digital network, the diversity of the Internet, composite, entertaining, interactive and virtual is deeply attracted college students, the network environment for college students' attitude toward life is happening. At present, many scholars have carried on the discussion to the university student's sports life attitude from the different angle of view. The attitude of sports life as the college students' psychological tendency to sports activities reflects the enthusiasm of college students to participate in sports activities.

Table 4. College Students' Attitude Towards Sports

\begin{tabular}{|c|c|c|c|c|c|}
\hline Attitude & $\begin{array}{c}\text { Very } \\
\text { positive }\end{array}$ & Positive & General & Negative & $\begin{array}{c}\text { Very } \\
\text { negative }\end{array}$ \\
\hline number & 114 & 345 & 98 & 16 & 2 \\
\hline Percent & 19.83 & 60 & 17.04 & 2.78 & 0.35 \\
\hline
\end{tabular}

College Students' sports motivation is the internal motivation of College Students' participation in sports activities. It plays an important role in the college students' physical exercise and the effect of physical exercise. From Table 5 can be seen, college students to participate in sports activities of the motivation to strong physique, the average selection coefficient reached 2.43 , followed by leisure entertainment, the average selection coefficient reached 2.21, as well as relieve decompression, prevention of diseases, personal hobbies, etc.. College Students' choice of sports motivation is closely related to sports entertainment, fitness, and communication function, and it also shows that the students' sports values have some degree of consistency, which fully reflects the students' motivation to participate in sports is positive and healthy.

Table 5. College Students' Attitude Towards Sports

\begin{tabular}{|c|c|c|c|}
\hline Motivation & number & Coefficient & sort \\
\hline Strong physique & 180 & 2.43 & 1 \\
\hline Recreation \& Entertainment & 164 & 2.21 & 2 \\
\hline Relieve decompression & 129 & 1.71 & 3 \\
\hline Prevention of disease & 65 & 0.88 & 4 \\
\hline Personal hobby & 48 & 0.65 & 5 \\
\hline
\end{tabular}

\subsection{College Students Participate in Sports Activities}

Students participating in this study, weekly frequency of physical activity were also studied. The results show that there are differences between male and female students also participate in the weekly frequency of physical activity. Boys participate in sports activities weekly frequency between 2-3 times mainly girls participate in sports activities time to focus on 1-2 times. Boys on exercise frequency was significantly better than girls, boys are more likely to form relatively Physical Exercise habit. By type of situation college students 'participation survey projects can be seen in Table 6, the type of college students' participation project is very extensive, the highest participation in the project is football, followed by badminton, basketball, Bingbing ball, ball can be seen the highest participation project.

Table 6. Survey of College Students' Participation in Sports Events

\begin{tabular}{|c|c|c|c|}
\hline Project & number & Coefficient & sort \\
\hline Basketball & 135 & 1.34 & 3 \\
\hline Volleyball & 35 & 0.35 & 6 \\
\hline Football & 169 & 1.63 & 1 \\
\hline
\end{tabular}




\begin{tabular}{|c|c|c|c|}
\hline Aerobics & 81 & 0.78 & 5 \\
\hline Badminton & 144 & 1.43 & 2 \\
\hline Bing Bing & 125 & 1.23 & 4 \\
\hline
\end{tabular}

\subsection{Correlation Analysis}

In order to better explain the relationship between College Students' Internet content and college students' sports values, the results showed that the content of Internet access was significantly related to the college students' sports values by Pearson correlation analysis.

Table 7. Correlation between the Internet and Students' Sports Values

\begin{tabular}{|c|c|c|c|c|c|c|}
\hline & Knowledge & News & Entertainment & Service & Comprehensive & Others \\
\hline $\begin{array}{c}\text { Pearson } \\
\text { correlation }\end{array}$ & $0.042^{* *}$ & $0.085^{* *}$ & $0.034^{*}$ & $0.086^{* *}$ & $0.062^{*}$ & $0.071^{*}$ \\
\hline Significant & 0.002 & 0.000 & 0.014 & 0.000 & 0.003 & 0.013 \\
\hline
\end{tabular}

Through the hypothesis test, there is a significant positive correlation between the Internet and college students' sports life style. The Internet and college students' sports values, sports attitude, sports interest, sports motivation, activity frequency, activity intensity, activity intensity type are significantly positive correlation with the 0.01 level, the Internet and college student's sports consumption is significantly positive correlation. The traditional education and college students' sports values, sports interest, sports participation in the activities of the project type is significantly positively related to the level of 0.05 . But the traditional education and college students' sports attitude, sports motivation, activity time, activity frequency, activity intensity, sports consumption has no obvious correlation. Through comparison, it can be seen that the difference between the Internet and traditional education on College Students' sports life style.

Table 8. Correlation between the Internet, Traditional Education and Sports

\begin{tabular}{|c|c|c|c|c|}
\hline \multirow{2}{*}{ Variable } & \multicolumn{2}{|c|}{ Traditional education } & \multicolumn{2}{c|}{ Internet } \\
\cline { 2 - 5 } & Corr.coef. & P value & Corr.coef. & P value \\
\hline Sports values & $0.241^{*}$ & 0.046 & $0.257^{* *}$ & 0.000 \\
\hline Sports attitude & 0.387 & 0.078 & $0.369^{* *}$ & 0.000 \\
\hline Sports interest & $0.434^{*}$ & 0.041 & $0.484^{* *}$ & 0.000 \\
\hline Sports motivation & 0.245 & 0.049 & $0.571^{* *}$ & 0.002 \\
\hline active time & 0.372 & 0.091 & $0.438^{* *}$ & 0.004 \\
\hline activity intensity & 0.169 & 0.069 & $0.359^{* *}$ & 0.002 \\
\hline activity type & $0.355^{*}$ & 0.038 & $0.141^{* *}$ & 0.000 \\
\hline Sports consumption & 0.724 & 0.071 & $0.396^{*}$ & 0.014 \\
\hline
\end{tabular}

\section{Conclusion}

On the Internet in China, sports information is rich, but the development and utilization of sports information resources lags behind, only to establish a correct concept of sports values, to produce a positive effect on the sports behavior, and promote the formation of College Students' sports life consciousness. With the rich and development of education network, the construction of network education in Colleges and universities has caused the attention of the relevant institutions. According to the survey, college students receive new knowledge active in extra-curricular, and this knowledge and from the network. Therefore, the full use of the advantages of network technology to enrich college students' learning style and learning way is completely feasible. The results of 
this study show that the Internet terminal, such as mobile phones and computers, has been very popular among college students, and college students have a long time to contact the network. Boys tend to play on the Internet, girls tend to shop. College Students' access to the Internet sports information content is mainly knowledge, education, news, comprehensive, reviews, service, entertainment and other categories. College Students' leisure time is mainly used to study, followed by the Internet, sports training, entertainment and other. College students choose sports activities in the field of free places, followed by public free places and profitable places. College Students' Internet access time, frequency of use, and the interaction between the time and the frequency of use are all significant influence on College Students' sports values, sports motivation, sports interest, sports attitude, participation activities, activity intensity, sports consumption and sports activities. Through comparison, it can be seen that the difference between the Internet and traditional education on College Students' sports life style.

Network physical education is a new education method, and the construction of the network physical education classroom should be the most important in the physical education in Colleges and universities. Modern education pays great attention to carry forward the main body of the students, respect students' personality, admit students' individual differences, and pay attention to the development of students' personality. At present, physical education in Colleges and universities must meet the needs of the students' physical and mental development. Therefore, schools and teachers should as much as possible to create conditions, through the network of modern teaching means, teaching according to students' situation, for students to provide different sports learning objectives, contents and methods, conducive to the development of their sports talent. Online physical education is the teacher's Guide to the network, so that students can understand the whole process of teaching physical education. The students can also put forward their own views and suggestions on the arrangement of the teacher's guide, to maximize the dual interaction between teaching and learning.

\section{References}

[1] B. Ma and Q. Wei, "Measuring the coverage and redundancy of information search services on ecommerce platforms", Electronic Commerce Research and Applications, vol. 11, no. 6, (2012), pp. 560-569.

[2] S. Nader, "A customer loyalty formation model in electronic commerce", Economic Modelling, vol. 35, (2013), pp. 559-564.

[3] K. Anand, "Context-general and Context-specific Determinants of Online Satisfaction and Loyalty for Commerce and Content Sites", Journal of Interactive Marketing, vol. 24, no. 3, (2010), pp. 222-238.

[4] Y. Zhang and J. Bian, "Trust fraud: A crucial challenge for China's e-commerce market", Electronic Commerce Research and Applications, vol. 12, no. 5, (2013), pp. 299-308.

[5] R. Ramanathan, "An empirical analysis on the influence of risk on relationships between handling of product returns and customer loyalty in E-commerce", International Journal of Production Economics, vol. 130, no. 2, (2011), pp. 255-261.

[6] D. Jutla and P. Bodorik, "Developing internet e-commerce benchmarks", Information Systems, vol. 24, no. 6, (1999), pp. 475-493.

[7] Z. Huang and M. Benyoucef, "From e-commerce to social commerce: A close look at design features", Electronic Commerce Research and Applications, vol. 12, no. 4, (2013), pp. 246-259.

[8] J. Kim, "The role of etail quality, e-satisfaction and e-trust in online loyalty development process", Journal of Retailing and Consumer Services, vol. 16, no. 4, (2009), pp. 239-247.

[9] L, Louis and É. Lefebvre, "Exploring B-to-B e-commerce adoption trajectories in manufacturing SMEs", Technovation, vol. 25, no. 12, (2005), pp. 1443-1456.

[10] D. Rosaci, "Multi-agent technology and ontologies to support personalization in B2C E-Commerce", Electronic Commerce Research and Applications, vol. 13, no. 1, (2014), pp. 13-23.

[11] L. Michel and R. Mohammad, "The effects of social media based brand communities on brand community markers, value creation practices, brand trust and brand loyalty", Computers in Human Behavior, vol. 28, no. 5, (2012), pp. 1755-1767.

[12] A. Niklas and S. Fredrik, "Electronic commerce, marketing channels and logistics platform-a wholesaler perspective", European Journal of Operational Research, vol. 144, no. 2, (2003), pp. 270279. 


\section{Author}

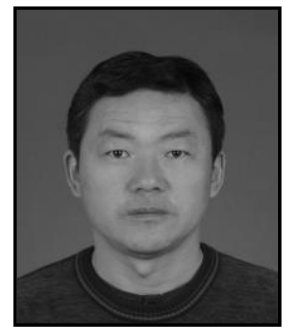

Yadong Ren, He is born in 1972, now he is the associate professor in Institute of physical education, Huaiyin Normal University. His research interest: physical education training. Email:jlryd@163.com. 
International Journal of Security and Its Applications

Vol. 10, No. 6 (2016) 